\title{
Toxin Profile of Gymnodinium catenatum (Dinophyceae) from the Portuguese Coast, as Determined by Liquid Chromatography Tandem Mass Spectrometry
}

\section{Pedro R. Costa ${ }^{1}$, Alison Robertson ${ }^{2, *}$ and Michael A. Quilliam ${ }^{3}$}

1 IPMA - Portuguese Institute of Ocean and Atmosphere/CCMAR - Centre of Marine Sciences Avenida de Brasília s/n, 1449-006 Lisbon, Portugal; E-Mail: prcosta@ipma.pt

2 Department of Marine Sciences, University of South Alabama, 5871 University Drive North, Mobile, AL 36688, USA

3 National Research Council of Canada, Measurement Science and Standards, Biotoxin Metrology, 1411 Oxford Street, Halifax, NS B3H 3Z1, Canada;

E-Mail: michael.quilliam@nrc.gc.ca

* Author to whom correspondence should be addressed; E-Mail: alisonrobertson@southalabama.edu; Tel.: +1-251-861-2141.

Academic Editor: Alejandro Mayer

Received: 11 December 2014 / Accepted: 27 March 2015 / Published: 13 April 2015

\begin{abstract}
The marine dinoflagellate Gymnodinium catenatum has been associated with paralytic shellfish poisoning (PSP) outbreaks in Portuguese waters for many years. PSP syndrome is caused by consumption of seafood contaminated with paralytic shellfish toxins (PSTs), a suite of potent neurotoxins. Gymnodinium catenatum was frequently reported along the Portuguese coast throughout the late 1980s and early 1990s, but was absent between 1995 and 2005. Since this time, G. catenatum blooms have been recurrent, causing contamination of fishery resources along the Atlantic coast of Portugal. The aim of this study was to evaluate the toxin profile of G. catenatum isolated from the Portuguese coast before and after the 10-year hiatus to determine changes and potential impacts for the region. Hydrophilic interaction liquid chromatography tandem mass spectrometry (HILIC-MS/MS) was utilized to determine the presence of any known and emerging PSTs in sample extracts. Several PST derivatives were identified, including the $N$-sulfocarbamoyl analogues (C1-4), gonyautoxin 5 (GTX5), gonyautoxin 6 (GTX6), and decarbamoyl derivatives, decarbamoyl saxitoxin (dcSTX), decarbamoyl neosaxitoxin (dcNeo) and decarbamoyl gonyautoxin 3 (dcGTX3). In addition, three known hydroxy benzoate
\end{abstract}


derivatives, G. catenatum toxin 1 (GC1), GC2 and GC3, were confirmed in cultured and wild strains of $G$. catenatum. Moreover, two presumed $N$-hydroxylated analogues of GC2 and GC3, designated GC5 and GC6, are reported. This work contributes to our understanding of the toxigenicity of $G$. catenatum in the coastal waters of Portugal and provides valuable information on emerging PST classes that may be relevant for routine monitoring programs tasked with the prevention and control of marine toxins in fish and shellfish.

Keywords: paralytic shellfish poisoning; paralytic shellfish toxins; phytoplankton; shellfish; harmful algal blooms; Gymnodinium catenatum; liquid chromatography-mass spectrometry

\section{Introduction}

The marine dinoflagellate Gymnodinium catenatum has received a lot of attention since it was associated with paralytic shellfish poisoning (PSP) in the late 1980s [1-3]. This algal species produces paralytic shellfish toxins (PSTs) that can accumulate in a variety of commercially harvested seafood species, such as bivalve mollusks. Consumption of contaminated shellfish may lead to severe poisonings, including fatalities [4-6]. The toxicity of PSTs is caused by a high affinity inhibition of voltage-gated sodium channels on the extracellular membrane of nerve cell terminals [7,8]. At low levels of exposure, these toxins can cause numbness of the fingers and extremities, tingling, nausea and vomiting; but at higher doses can result in muscular paralysis and death by respiratory paralysis and cardiovascular shock $[9,10]$.

The most prevalent PSTs can be divided into three groups based on structural differences in their functional groups, namely the carbamoyl, decarbamoyl and sulfocarbamoyl derivatives (Figure 1). Due to these structural differences, each toxin has a slightly different affinity to the binding site of voltage-gated sodium channels, which correlates to differential toxicity [11]. The carbamoyl group, which includes saxitoxin (STX), neosaxitoxin (Neo) and the gonyautoxins (GTX 1-4), are considered the most toxic due to the potent intra-peritoneal toxicity observed in mice [12] and affinity to the sodium channel, as recorded during patch clamp studies [13]. The $N$-sulfocarbamoyl PSTs includes the four C-toxins (C1-4), gonyautoxin-5 (GTX5, formerly B1) and gonyautoxin-6 (GTX-6, formerly B2). Based on intraperitoneal toxicity data, the decarbamoyl group in considered to have moderate toxicity and includes decarbamoyl-STX (dcSTX), decarbamoyl-GTXs (e.g., dcGTX1-4) and decarbamoyl-Neo (dcNeo) [12].

A novel group of PSTs were identified in strains of $G$. catenatum isolated from Australian waters and were named GC1, GC2 and GC3 based on the phytoplankton from which they were isolated [14]. These PSTs have the carbamate side chains substituted with a hydroxybenzoate moiety (see Figure 1). The toxicity of the hydroxybenzoate PSTs (GC toxins) is not well known; however, radio-receptor binding studies using rat brain synaptosomes enriched for sodium channels showed high affinity binding in previous studies [15]. In addition, the phenol ring that is incorporated into the molecule may facilitate transport and bioaccumulation of these compounds due to an increased lipophilicity compared 
to other PST derivatives [15]. The GC toxins have since been identified in strains of G. catenatum isolated from Portugal, Spain, China, Japan and Uruguay [16].

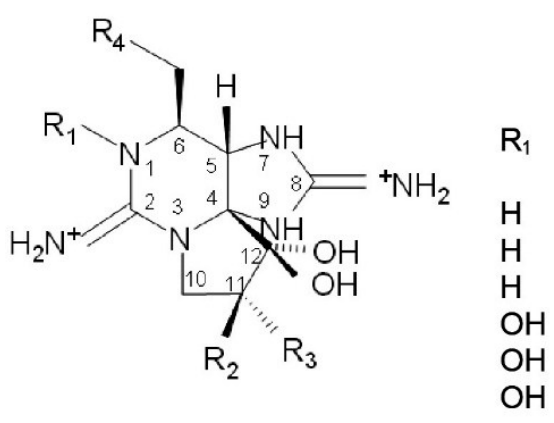

\begin{tabular}{|c|c|c|c|c|c|}
\hline & & $\mathrm{R}_{4}$ & & & \\
\hline o & $\mathrm{R}_{3}$ & Carbamoyl & Sulfocarbamoyl & $\begin{array}{l}\text { Decarbamoyl } \\
-\mathrm{OH}\end{array}$ & ৪০a \\
\hline $\begin{array}{l}\mathrm{H} \\
\mathrm{H} \\
\mathrm{OSO}_{3}^{-} \\
\mathrm{H} \\
\mathrm{H} \\
\mathrm{OSO}_{3}^{-}\end{array}$ & $\begin{array}{l}\mathrm{H} \\
\mathrm{OSO}_{3}^{-} \\
\mathrm{H} \\
\mathrm{H} \\
\mathrm{OSO}_{3}^{-} \\
\mathrm{H}\end{array}$ & $\begin{array}{l}\text { STX } \\
\text { GTX2 } \\
\text { GTX3 } \\
\text { Neo } \\
\text { GTX1 } \\
\text { GTX4 }\end{array}$ & $\begin{array}{c}\text { GTX5 } \\
\text { C1 } \\
\text { C2 } \\
\text { GTX6 } \\
\text { C3 } \\
\text { C4 }\end{array}$ & $\begin{array}{l}\text { dcSTX } \\
\text { dcGTX2 } \\
\text { dcGTX3 } \\
\text { dcNeo } \\
\text { dcGTX1 } \\
\text { dcGTX4 }\end{array}$ & $\begin{array}{l}\text { GC3 } \\
\text { GC1 } \\
\text { GC2 } \\
\text { GC6* } \\
\text { GC4* } \\
\text { GC5* }\end{array}$ \\
\hline
\end{tabular}

Figure 1. Structure of paralytic shellfish poisoning (PSP) toxins. STX, saxitoxin; GTX, gonyautoxin; Neo, neosaxitoxin; dc, decarbamoyl; GC, G. catenatum toxin. * Theoretical chemical structures of GC4, GC5, and GC6, suggested by [17].

Paralytic shellfish poisoning occurs worldwide, and harmful algal blooms, including those responsible for PSP, appear to be increasing in frequency and intensity $[18,19]$. PSP outbreaks in Portuguese waters have been associated with blooms of Gymnodinium catenatum in the late 1980s to early 1990s, then again after 2005 [2,20,21]. According to the national monitoring program in Portugal, G. catenatum were not reported along the Portuguese coast during the 10 -year period from 1995 to 2005 [22]. The aims of this study were to fully characterize the toxin profile of G. catenatum strains isolated from the NW Portuguese coast before and after the 10-year absence of blooms to determine changes and potential implications for the region. Hydrophilic interaction liquid chromatography tandem mass spectrometry (HILIC-MS/MS) was utilized to determine the presence of any known and emerging PSTs in sample extracts.

\section{Results and Discussion}

\subsection{Identification of "Classic” PSTs in G. catenatum}

The profile of PSTs in a cultured strain of Gymnodinium catenatum isolated from Cascais Bay in 2007 and a seawater sample collected during a bloom of $G$. catenatum off Aveiro also in 2007 was characterized via HILIC-MS/MS. After having optimized the MS parameters, different MS modes were used for the analysis of the algae extracts. Starting from the full scan mode, one can obtain information about the ions formed in the ion source, which is necessary for further developing MRM acquisitions. The G. catenatum isolated from Portuguese waters was found to produce at least 14 compounds that are structurally related with saxitoxin. Data obtained by tandem mass spectrometry revealed a profile of PSTs in wild and cultured strains constituted by $N$-sulfocarbamoyl and decarbamoyl toxin analogues, namely C1-4, GTX5, GTX6, dcSTX, dcNeo and dcGTX3 (Figure 2). The ion transitions giving optimal results are illustrated in Figure 3. Identification was based on a match of retention times, MRM transition ratios and full scan spectra with those of standards. Carbamate toxins, such as STX or Neo, were not detected in the samples analyzed. 

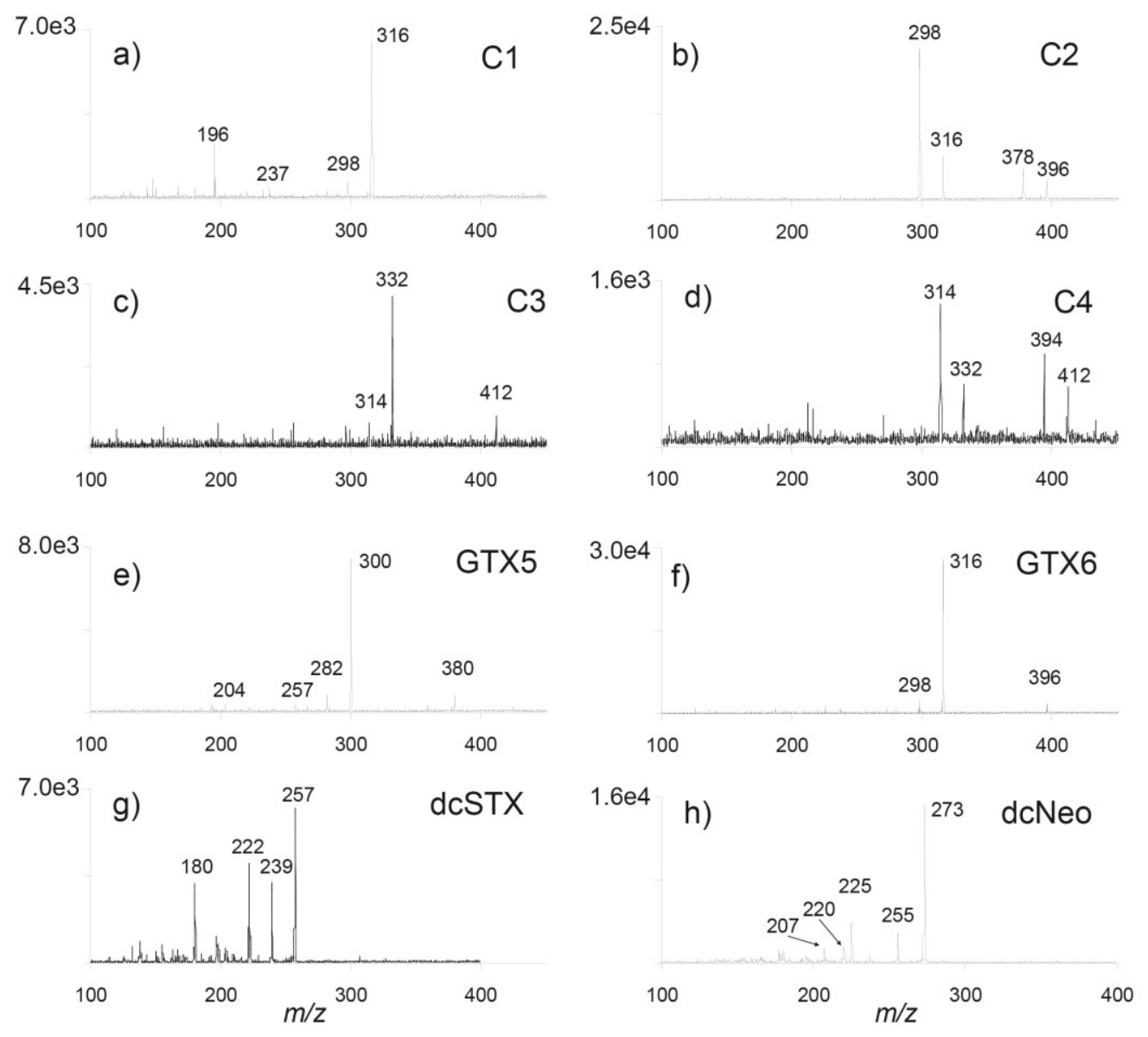

Figure 2. Product ion spectra of paralytic shellfish toxins identified in a Gymnodinium catenatum culture isolated from the Portuguese coast in 2007: (a) $\mathrm{m} / \mathrm{z} 316$ of $\mathrm{C} 1$; (b) $\mathrm{m} / \mathrm{z} 396$ of C2; (c) $\mathrm{m} / \mathrm{z} 412$ of C3; (d) $\mathrm{m} / \mathrm{z} 412$ of C4; (e) $\mathrm{m} / \mathrm{z} 380$ of GTX5; (f) $\mathrm{m} / \mathrm{z} 396$ of GTX6; (g) $m / z 257$ of dcSTX; and (h) $m / z 273$ of dcNeo. The $[\mathrm{M}+\mathrm{H}]^{+}$ions were selected from full scan analyses and fragmented to achieve the maximum abundance of product ions.

\subsection{Identification of Hydroxybenzoate PSTs in Portuguese G. catenatum}

In addition to the above reported $N$-sulfocarbamoyl and decarbamoyl toxins, the three hydroxybenzoate derivatives described by [14], i.e., GC1-3, were also identified in the extracts of G. catenatum. The structural information from the MS/MS product ion spectrum revealed three or more diagnostic ion fragments for each compound (Figure 4). The MRM method was then optimized based on product ion scans. The ion transitions giving optimal results are illustrated in Figure 5. Identification of GC1-3 was confirmed by a good match of retention times, MRM transition ratios and full scan spectra with those of standards produced in the earlier study [14]. 


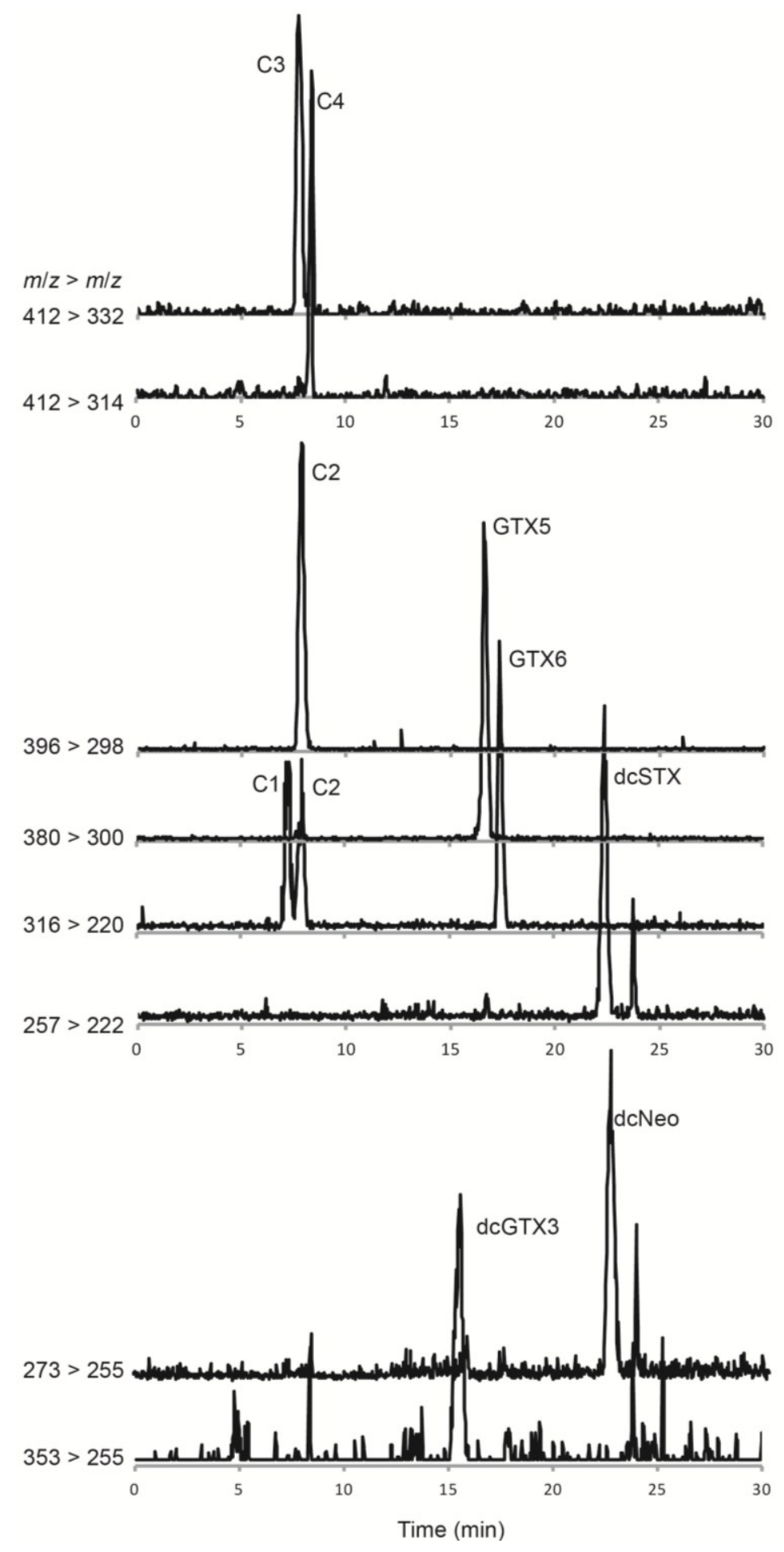

Figure 3. Hydrophilic interaction liquid ion chromatography mass spectrometry analysis of paralytic shellfish toxins in a Gymnodinium catenatum culture isolated from the Portuguese coast in 2007. Multiple reaction monitoring in positive polarity was used to identify toxin derivatives. At least two confirmatory ion transitions were monitored for each paralytic shellfish toxin (PST) derivative. The primary transition ions are shown for all confirmed toxins in the samples: $m / z 257>222$ for dcSTX, $m / z 273>255$ for $\mathrm{dcNeo}, m / z 316>220$ for C1 and GTX6, $m / z 353>255$ for dcGTX3, $m / z 380>300$ for GTX5, $m / z 396>298$ for $\mathrm{C} 2, m / z 412>314$ for $\mathrm{C} 4$ and $m / z 412>332$ for C3 (see Table 2 for details on the MS/MS parameters). 

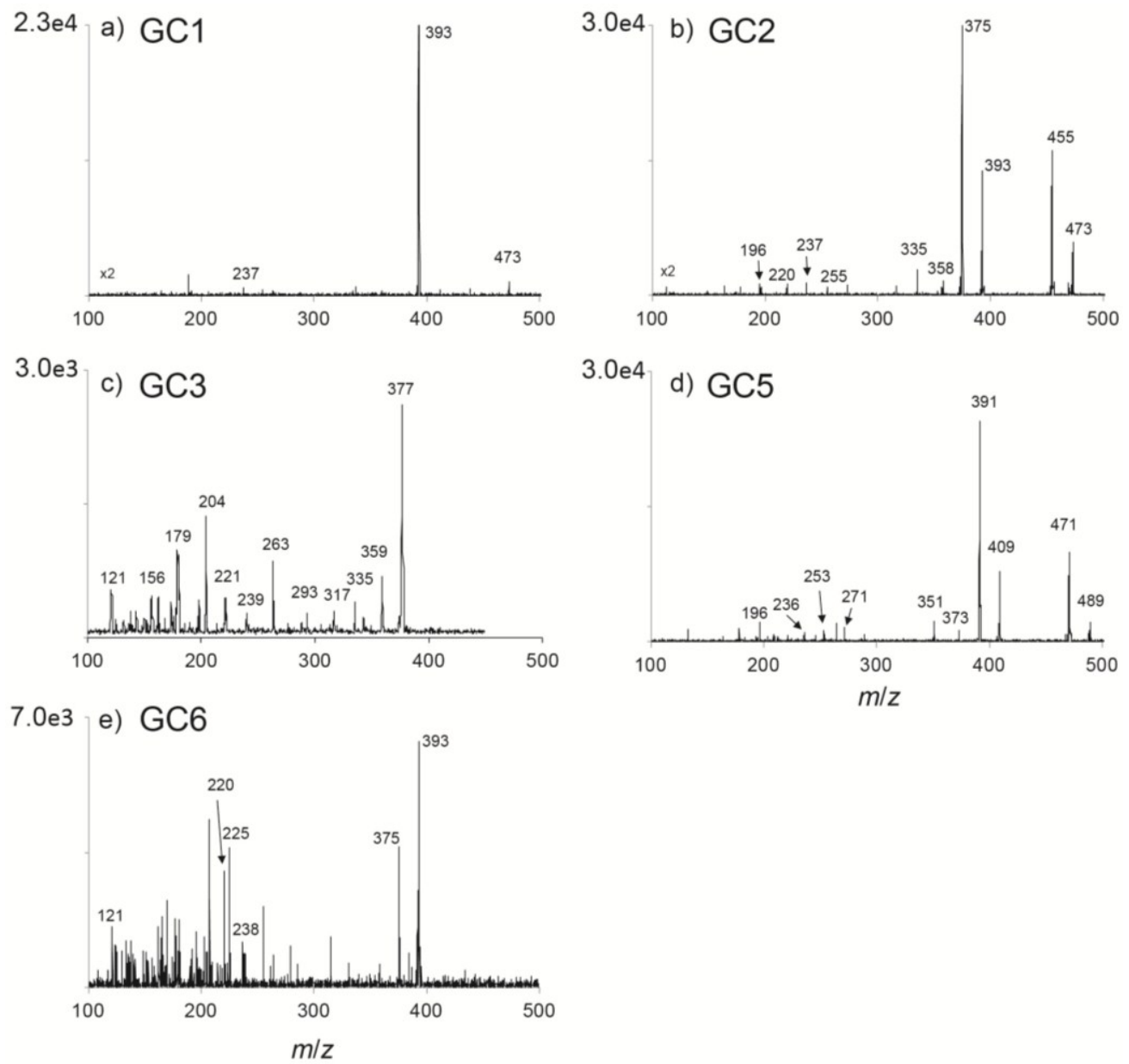

Figure 4. Product ion spectra of GC toxins identified in a Gymnodinium catenatum culture isolated from the Portuguese coast in 2007: (a) $\mathrm{m} / \mathrm{z} 473$ of GC1; (b) $\mathrm{m} / \mathrm{z} 473$ of GC2; and (c) $m / z 377$ of GC3; (d) $m / z 489$ of GC5; and (e) $m / z 393$ of GC6. The $[\mathrm{M}+\mathrm{H}]^{+}$ions were selected from full scan analyses and fragmented to achieve the maximum abundance of product ions.

A late eluting peak in the $\mathrm{GC} 1$ ion transition was observed, which, after subsequent full scan and product ion scans, was revealed to be due to GC6, as theoretically reported by [17]. The MS/MS product ion spectrum of the $[\mathrm{M}+\mathrm{H}]^{+}$ion of GC6 shows a dominant fragment at $\mathrm{m} / z 375$, which is due to the loss of a water molecule (Figure 4). Additional fragments are coincident to GC1 and GC2 isomers allowing detection of GC6 in MRM transitions, such as $m / z 393>220$ (Figure 5). In support of the structure being assigned as GC6, the shift of $\mathrm{m} / \mathrm{z} 204$ in the GC3 spectrum to $\mathrm{m} / \mathrm{z} 220$ in the new compound supports the location of the extra hydroxyl being in the main ring and not on the side chain. The most likely location that conforms to other PST structures is on N1, i.e., a Neo analogue. In addition, the retention time of the compound is slightly greater than GC3, which is consistent with the GC6 structure, as evidenced by the retention time relationship between Neo and STX. 


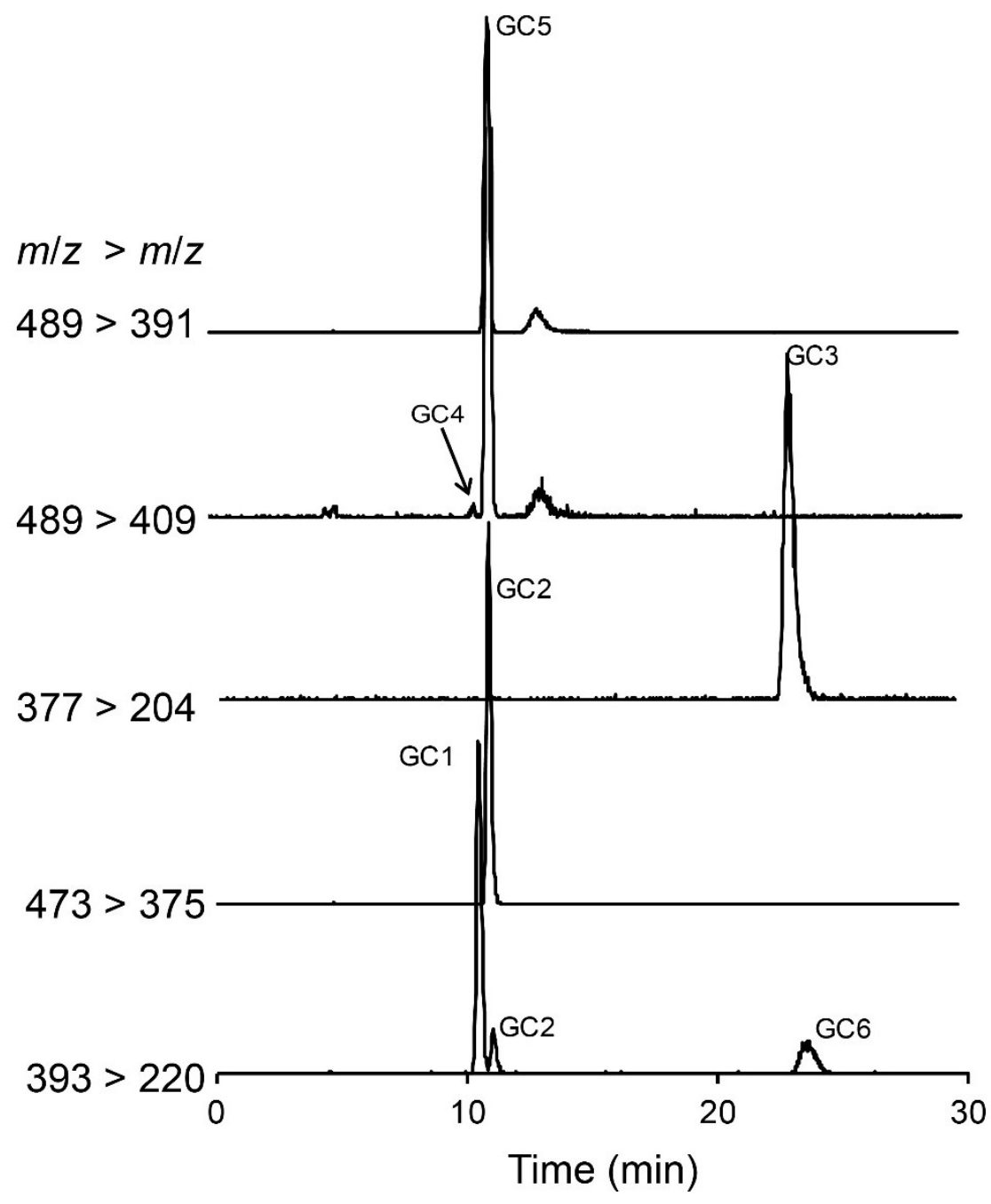

Figure 5. Hydrophilic interaction liquid ion chromatography-mass spectrometry analysis of paralytic shellfish toxins in a Gymnodinium catenatum culture isolated from the Portuguese coast in 2007. Multiple reaction monitoring in positive polarity was used to identify hydroxybenzoate PST analogues GC1-6 that were detected and confirmed in a Gymnodinium catenatum culture isolated from the Portuguese coast. Primary ion transitions are shown: $m / z 377>204$ for GC3; $m / z 393>220$ for GC1 and GC6; $m / z 473>375$ for GC2, $m / z 489>409$ for GC4 and 5, m/z $489>391$ for GC5 (see Table 2 for details on the MS/MS parameters).

During full scan analysis of the algae extract, an $[\mathrm{M}+\mathrm{H}]^{+}$ion at $\mathrm{m} / \mathrm{z} 489$ was also observed. This most likely corresponds to the theorized GC5 derivative [17]. Characteristic fragmentation during product ion scans confirmed that this was highly likely to be GC5 (see Figure 4). The MS/MS product ion spectrum showed prominent fragment ions at $\mathrm{m} / \mathrm{z} 471$ (loss of $\mathrm{H}_{2} \mathrm{O}$ ), $\mathrm{m} / z 409$ (loss of $\mathrm{SO}_{3}$ ) and $m / z 391$ (loss $\mathrm{SO}_{3}+\mathrm{H}_{2} \mathrm{O}$ ). In support of the structure being assigned as GC5, the shift of $m / z 220$ in the GC2 spectrum to $\mathrm{m} / \mathrm{z} 236$ in the new compound supports the location of the extra hydroxyl being in the main ring and not on the side chain. The most likely location that conforms to other PST structures is on N1, i.e., a GTX4 analogue. The retention time of this compound is slightly greater than $\mathrm{GC} 2$, which is also consistent with the GC5 structure. 
Dinoflagellates have been shown to produce $\beta$-epimer forms of PSTs in higher abundance than $\alpha$-epimers, which are thought to arise through epimerization [23]. Our data were consistent with this assumption with C2, C4, dcGTX3, GC2 and GC5 identified in the G. catenatum extracts (see Figure 3). Due to epimerization within living cells or under extraction conditions, the $\alpha$-analogues can also be detected [23,24]. In our study, the $\alpha$-analogues C1 and GC1 of the abundant C2 and GC2 compounds were detected in the algal extract. The level of dcGTX3 in our samples was very low, so as expected, the $\alpha$-analogue, dcGTX2 was below our detection limits. Similarly, a peak corresponding to the putative GC5 was identified, but only trace levels of GC4 were found. A small peak in the MRM transition $\mathrm{m} / z 489>409$ was observed to elute just before GC5 that corresponds to the putative GC4 (see Figure 5).

One of the aims of this study was deciphering the presence of benzoate derivatives. Particular heed was taken to the search for isoforms with the hydroxyl group replaced by a hydroxyl sulfate group in the benzoate side chain. These compounds would be designated as GC7-12. However, MS/MS analysis did not show their presence in the extracts analyzed, though the theoretical existence of more than 18 benzoate analogues was previously proposed [17].

\subsection{Understanding Gymnodinium catenatum Bloom Hiatus in Portuguese Waters}

Although it was described for the first time in Gulf of California, Mexico, in 1939 [25], Gymnodinium catenatum was only associated with PSP episodes in 1976 in Galicia, NW Spain, and then in 1986 in Portugal [1,2]. This species was since then reported with increasing frequency and geographic distribution, including Australia, Japan, South America (Venezuela, Uruguay) and the tropical Indo-West Pacific (Philippines, Singapore and Malaysia) [26]. Marked differences in the profile of PSP toxins have been observed among these regions [16]. Therefore, PSP toxin phenotypes may be used to understand species introduction, migration or adaptation to environments.

The European origin of $G$. catenatum remains unclear. Cyst records in dated sediment cores indicate that the arrival of $G$. catenatum to the south Iberian coast, expanding then northwards, was in $1889 \pm 10[27,28]$. After the first bloom of G. catenatum detected in the Portuguese coast in 1985, the species was recurrently registered in the NW coast until 1992, when blooms of G. catenatum were also detected in the south and southwest coast [20,29]. Despite the maintenance of a regular monitoring program for toxic algae, no evident blooms of G. catenatum were observed between 1996 and late 2005 [22]. In order to understand the resurgence of G. catenatum after a 10-year hiatus of absence, the profile of PSP toxins determined in this study was compared with previous studies where G. catenatum strains isolated before 1995 were analyzed (Table 1). In the present study, the dominant compounds, in terms of molar fraction, were GC1-3, C1, C2, and GTX5 in both wild and cultured strains (Table 1). Characterization of the profile of toxins produced by G. catenatum isolated from the Portuguese coast was firstly carried out by post-column LC-FLD analysis [30]. At a time when standards and confirmatory methods were limited, the profile of toxins was constituted only by the C1, C2, dcSTX and GTX5. More recently, several $N$-sulfocarbamoyl, decarbamoyl and hydroxybenzoate toxins were determined in a $G$. catenatum strain isolated from the Portuguese coast in 1989 [16]. The toxins identified in these two previous studies are in accordance with the findings of the present study. 
Table 1. Toxin profile (mol\%) from the Gymnodinium catenatum culture isolated from Cascais Bay in 2007, a seawater sample collected during a bloom of G. catenatum off Aveiro in 2007 and a strain isolated from Aguda in 1989 that was cultured and analyzed by [16].

\begin{tabular}{|c|c|c|c|c|c|}
\hline \multirow{3}{*}{ Toxin } & \multirow{2}{*}{\multicolumn{2}{|c|}{$\frac{\text { Toxin Cell Quota }(\mathrm{fmol} / \text { Cell })^{\wedge}}{\text { This Study }}$}} & \multicolumn{3}{|c|}{ Toxin Profile (mol\%) } \\
\hline & & & \multicolumn{2}{|c|}{ This Study } & \multirow{2}{*}{$\frac{\text { Negri et al. (2007) }}{\text { Culture (1989) }}$} \\
\hline & Culture & Seawater & Culture & Seawater & \\
\hline $\mathrm{C} 1+2$ & 6.5 & 4.3 & 21.0 & 22.1 & 14.5 \\
\hline $\mathrm{C} 3+4$ & 0.5 & 0.4 & 1.6 & 2.0 & 6.0 \\
\hline $\mathrm{GTX} 2+3$ & nd & nd & nd & nd & 1.0 \\
\hline GTX5 & 3.4 & 6.9 & 11.0 & 35.2 & 12.9 \\
\hline GTX6 & 1.2 & nd & 3.8 & nd & 5.9 \\
\hline $\mathrm{dcGTX} 2+3$ & 0.3 & nd & 0.8 & nd & 4.0 \\
\hline dcSTX & 2.2 & nd & 7.2 & nd & 2.5 \\
\hline dcNeo & 1.1 & nd & 3.4 & nd & nd \\
\hline STX & nd & nd & nd & nd & 0.4 \\
\hline $\mathrm{GC} 1+2$ & 5.9 & 6.2 & 19.0 & 31.6 & 35.3 \\
\hline GC3 & 5.0 & 1.6 & 16.2 & 8.3 & 17.6 \\
\hline $\mathrm{GC} 4 *+5$ & 1.7 & 0.2 & 5.6 & 0.8 & na \\
\hline GC6 & 3.2 & nd & 10.3 & nd & na \\
\hline
\end{tabular}

nd: not detected; na: not analyzed; * trace level GC4 detected, but not in the quantifiable range;

$\wedge$ LC-MS/MS peak area for individual PSTs was compared to the corresponding toxin standard curves to calculate the concentration $(\mu \mathrm{M})$, then standardized to the combined total fraction as a percentage to calculate the $\mathrm{mol} \%$ as detailed in the Experimental Section.

Although variations of the PST profile in terms of the relative abundance of each toxin are expected to occur with $G$. catenatum growth phases, cell culture age or nutrient availability [31,32], there is consistency of the suite of toxins within populations [33,34]. The same suite of PSTs was found in the culture of a strain isolated in 2007 (this study), in a seawater sample collected during a bloom of G. catenatum in 2007 (this study) and strains isolated before the 10-year hiatus, as reported by [16] and by the early studies performed by [30]. Using the toxin profile as the chemical signature, the recent resurging of $G$. catenatum in the Portuguese coast should not be viewed as a result of a reintroduction of the species from other regions, such as for example via ship ballast waters. The explanation for this discontinuing occurrence still needs to be elucidated. One hypothesis may be related to an important feature in the life-cycle of $G$. catenatum, which is the formation of a non-motile resting cyst that is resistant to degradation and may persist to be viable in sediments $[35,36]$.

\subsection{Management Implications}

From the pool of the toxins detected, only six are routinely monitored in Portuguese shellfish via the conventional HPLC-FLD method developed by Lawrence [37]. Attempting to move away from animal testing, the HPLC-FLD method was accepted by European directives as an alternative to the mouse bioassay (MBA) for the determination of PSP toxins in shellfish [38]. However, determination of the entire range of toxins present in the matrix is required for the assessment of the risk associated with the 
human consumption of shellfish. In this study, the presence of toxins for which commercial standards were not previously available, i.e., $\mathrm{C} 3, \mathrm{C} 4$, GTX6 and the $\mathrm{GC}$ toxins, GC1, GC2, GC3, GC4, GC5 and GC6, were confidently identified in G. catenatum extracts. These toxins are not part of the routine PSP monitoring in many regions due to the lack of analytical standards, but they may be important contributors to the composite toxicity of shellfish. Fortunately, we were able to use certified reference materials for 12 of the 18 PST derivatives investigated during this study. Although the $\mathrm{N}$-sulfocarbamoyl analogues C3 and C4 and GTX6 are considered less toxic than most other PSTs [12,39], the high concentrations reached in mussels exposed to G. catenatum blooms showed a significant contribution of these low potency analogues to the PSP toxicity of the sample in our previous study [40]. Very little data exist on the bioaccumulation of GC toxin analogues, and no data exist for GC4-6 [6,41]. The observation of high levels of GC toxins found in G. catenatum from the Portuguese coast in this study requires an extensive follow-up investigation of trophic transfer in the marine food web, so that we may assess the potential human health risk. However, to date, only one study investigated the presence of GC toxins in shellfish and in sardine viscera [42]. In this study, shellfish samples collected from the Portuguese coast revealed that up to $18 \%$ of the total PST molar fraction was due to GC toxins, but quantification and confirmation was not possible, due to the lack of reference standards [42]. The less polar hydroxybenzoate moiety of GC toxins would favor its bioaccumulation and reduce their elimination rate $[14,15]$. Further research is needed to understand the dynamics of GC toxins accumulation, elimination and, indeed, their contribution to composite mammalian toxicity.

It is also important to review the detection methods used for routine analysis of food control. The reverse-phase SPE clean-ups used to remove interferences on the HPLC methods will result in the loss of these hydrophobic toxins, resulting in a potential underestimation of composite toxicity. More recently, another method that is an alternative to the MBA, the receptor binding assay for PST [43,44], has become an official method of the International Association of Analytical Chemists (AOAC International) (AOAC 2011.27). This biochemical method may be a good candidate for complex matrices containing multiple toxins, since its requirements in terms of standards are very simple, needing only for routine analysis the STX radiolabeled calibrant. A modified version of this method was used to assess the affinity of GC toxins 1-3 to the rat brain sodium channel [15]. These investigators found that the GC toxins had a high affinity (nanomolar range) in the receptor binding assay and concluded that an expected increase in lipophilicity gained by the addition of the phenol ring in the GC saxitoxin structure may increase the potential for bioaccumulation in seafood species. Discrimination of the toxin profile was not achieved through this method; however, there appears a good correlation between biological activity and toxicity for the entire range of PST [43].

\section{Experimental Section}

\subsection{Reagents and Standards}

All organic solvents were HPLC or LCMS grade. Water was distilled and passed through a MilliQ water purification system. Formic acid (LCMS grade) and acetic acid (AR grade) were purchased from Fisher Scientific (Pittsburgh, PA, USA). The following certified reference materials for PSTs were provided by the National Research Council (NRC) of Canada (Halifax, NS, Canada) and used 
throughout this study: CRM-STX-e, CRM-Neo-b, CRM-GTX2\&3-b, CRM-GTX1\&4-b, CRM-dcSTX, CRM-dcGTX2\&3, CRM-GTX5-b, CRM-C1\&2 and CRM-dcNeo-b. Reference standards for three GC-toxins (GC1-3) were also prepared by the NRC group and used throughout this study for the generation of standard curves and optimization of MS methods. The molar concentrations of GTX6, C3, C4, GC4, GC5 and GC6 was estimated using standards of structurally similar compounds, namely GTX5, C1, C2 and GC3, respectively. A similar molar and peak area response was assumed for these compounds.

\subsection{Sample Collection and Culture}

Surface seawater samples were collected during $G$. catenatum blooms along the NW Portuguese coast in 2007 [45]. Seawater samples containing the highest cell density of $2.5 \times 10^{4}$ cells of $G$. catenatum $\mathrm{L}^{-1}$ were chosen for this study. A $1.5 \mathrm{~L}$ volume of seawater was vacuum filtered on $0.45-\mu \mathrm{m}$ pore size mixed cellulose ester (HA) membrane filters (Durapore, EMD Millipore Inc., Boston, MA, USA) and frozen at $-20{ }^{\circ} \mathrm{C}$, as previously described [46]. Cultured strains were isolated from a $G$. catenatum bloom in Cascais Bay, Portugal, in September, 2007. Cells were grown in $\mathrm{f} / 2$ medium at $18{ }^{\circ} \mathrm{C}$ and $250 \mu \mathrm{E} \mathrm{m}^{-2} \mathrm{~s}^{-1}$ light with a $12: 12$ light:dark cycle. Cells were harvested from the 2 -L culture by centrifugation at $2000 \times \mathrm{g}$ for $5 \mathrm{~min}$ at $15^{\circ} \mathrm{C}$. The cell density of the cultured strain was $6.6 \times 10^{5}$ cells $\mathrm{L}^{-1}$.

\subsection{Chemical Extraction of PSTs}

Cell pellets and filters were extracted in $5 \mathrm{~mL}$ of $0.05 \mathrm{M}$ acetic acid using a probe sonicator at $25 \mathrm{~W}, 50 \%$ pulse duty cycle (Branson Sonifier 450, Danbury, NH, USA) for 4 min on ice. Cell lysis was confirmed using light microscopy. The extracts were then centrifuged at $4000 \times g$ for $10 \mathrm{~min}$, and the supernatant cleaned by solid phase extraction (SPE) using an octadecyl bonded phase silica (Supelclean LC-18 SPE cartridge, $3 \mathrm{~mL}$, Supelco, Sigma Aldrich, St. Louis, MO, USA) cartridge, which had been pre-conditioned with $6.0 \mathrm{~mL}$ methanol followed by $6.0 \mathrm{~mL}$ water. A $1.0-\mathrm{mL}$ aliquot of the extract was loaded onto the column and PSTs eluted with $2.0 \mathrm{~mL}$ of water as reported by [37]. Following a wash with $2.0 \mathrm{~mL}$ of water, the cartridges were then subjected to a second elution with $80 \% \mathrm{v} / \mathrm{v}$ aqueous methanol to capture any hydrophobic GC toxin derivatives. This fraction was then evaporated to dryness under $\mathrm{N}_{2(\mathrm{~g})}$ at room temperature and re-constituted in $0.5 \mathrm{~mL}$ water.

\subsection{Liquid Chromatography Tandem Mass Spectrometry}

Toxin analysis was performed on a Waters Acquity UPLC system coupled to a Waters Quattro Micro triple quadrupole mass spectrometer. The analytical method employed during this study was modified from similar protocols reported by $[47,48]$. A $5-\mu \mathrm{m}$ amide bonded silica (TSK-gel Amide- $80^{\circledR}$ ) column $(250 \mathrm{~mm}$ length $\times 2.0 \mathrm{~mm}$ i.d.) with a guard column $(2 \mathrm{~mm} \times 1 \mathrm{~cm})$ with the same stationary phase from Tosoh Bioscience (Grove, CA, USA) was selected. The column was maintained at $30{ }^{\circ} \mathrm{C}$, and a sample injection volume of $10 \mu \mathrm{L}$ was used. Toxins were eluted at a flow rate of $0.2 \mathrm{~mL} / \mathrm{min}$ with a normal phase gradient from $65 \% \mathrm{~B}$ to $35 \% \mathrm{~B}$ in $30 \mathrm{~min}$, followed by a 5 -min hold at $35 \% \mathrm{~B}$, where Mobile Phase A consisted of $50 \mathrm{mM}$ formic acid in water $(\mathrm{pH}=2.6)$ and Mobile Phase $\mathrm{B}$ 
consisted of $95 \%$ aqueous acetonitrile containing $50 \mathrm{mM}$ formic acid. Analyses were performed in positive ion mode using full scan, product ion scan and multiple reaction monitoring (MRM) experiments. The following MS source conditions were used for analysis: capillary voltage at $2.0 \mathrm{kV}$, source temperature $125^{\circ} \mathrm{C}$, desolvation temperature $390{ }^{\circ} \mathrm{C}$, cone gas flow $200 \mathrm{~L} \mathrm{~h}^{-1}$, desolvation gas flow at $500 \mathrm{~L} \mathrm{~h}^{-1}$, capillary voltage $2 \mathrm{kV}$. Transition ion selection for MRM experiments was determined following product ion scans, with cone voltage and collision energies optimized for each transition ion pair using NRC-certified reference materials and reference standards (Table 2). These standards were used in the method development to optimize the mass spectrometer conditions and spectra for survey scans (MS and MS/MS) and MRM analyses. In addition, reference standards were used to generate external calibration curves, for direct comparison of retention times and comparison of transition ion ratios in this study. The limit of detection (LOD, $S / N=3$ ) was calculated at $0.02 \mathrm{nM}$ for STX. The concentration of GTX6, C3, C4, GC4, GC5 and GC6 were estimated assuming an equal molar and peak response of structurally similar analogs, since certified reference standards were available for just 12 of the 18 toxins surveyed in this study. In these instances, the concentration was determined based on the calibration curves of the most structurally similar analog (i.e., adjusted to the known molecular weight of the toxin to determine the concentration. Minor sample matrix effects (e.g., ionization suppression and retention time shifts) were resolved with sample dilution (1:5 ratio) in the mobile phase, with resultant within- and between-day residuals for a retention time $>4 \%$. The concentration of individual PST derivatives is expressed on a per cell basis and as a molar percentage of the combined PST mixture identified in phytoplankton cultures and seawater. Data were acquired and post-processed using Waters MassLynx ${ }^{\mathrm{TM}}$ software, v. 4.1.

Table 2. Primary and secondary transition ion pairs for paralytic shellfish toxins (PSTs) analyzed by multiple reaction monitoring in this study, except those that were in low abundance or not detected in algae extracts. Optimized collision energy and declustering potential for each transition ion pair is provided.

\begin{tabular}{cccc}
\hline Toxin & Transition Ion Pair $(\boldsymbol{m} / \boldsymbol{z})$ & Collision Energy $(\mathbf{e V})$ & Declustering Potential $(\mathbf{V})$ \\
\hline dcSTX & $257>222$ & 19 & 35 \\
& $257>239$ & 10 & 30 \\
dcNeo & $273>255$ & 20 & 35 \\
& $273>225$ & 25 & 35 \\
STX & $300>204$ & 20 & 35 \\
GTX3 & $316>220$ & 20 & 35 \\
dcGTX3 & $353>255$ & 20 & 35 \\
GTX5 & $380>300$ & 14 & 20 \\
& $300>204$ & 20 & 35 \\
C2 & $396>298$ & 10 & 40 \\
& $396>316$ & 15 & 45 \\
C1 & $316>220$ & 20 & 35 \\
& $396>316$ & 15 & 45 \\
GTX6 & $316>220$ & 20 & 35 \\
& $396>316$ & 15 & 45 \\
\hline
\end{tabular}


Table 2. Cont.

\begin{tabular}{clll}
\hline C4 & $412>314$ & 10 & 40 \\
& $412>332$ & 15 & 45 \\
$\mathrm{C} 3$ & $412>332$ & 15 & 45 \\
$\mathrm{GC} 1$ & $393>320$ & 15 & 20 \\
& $473>393$ & 15 & 20 \\
$\mathrm{GC} 2$ & $473>375$ & 15 & 20 \\
& $473>455$ & 15 & 20 \\
$\mathrm{GC} 3$ & $377>204$ & 25 & 40 \\
& $377>359$ & 20 & 30 \\
$\mathrm{GC} 4$ & $489>409$ & 20 & 30 \\
$\mathrm{GC5}$ & $489>391$ & 20 & 30 \\
& $489>471$ & 15 & 20 \\
$\mathrm{GC} 6$ & $393>220$ & 20 & 40 \\
& $393>375$ & 15 & 20 \\
\hline
\end{tabular}

\section{Conclusions}

The HILIC-MSMS analyses performed to determine the profile of PSP toxins produced by G. catenatum from the Portuguese coast confirmed the dominant presence of the $N$-sulfocarbamoyl and hydroxybenzoate PSP analogues. The characterized profile resembles that of G. catenatum isolated in the Portuguese coast before the 10-year period of $G$. catenatum absence, suggesting that resurgence of this cryptogenic dinoflagellate is not a result of reintroduction or new import from other regions. Two new hydroxybenzoate analogues, GC5 and GC6, were characterized for the first time through tandem mass spectrometry. Based on the estimated molar fraction, these benzoate analogues were the major constituents of the G. catenatum strains analyzed, and they pose a new challenge from a monitoring and regulatory perspective. The reduced knowledge of their toxicity, the lack of analytical certified standards for GC toxins in addition to the diverse nature, i.e., hydrophilic and hydrophobic, of the entire range of compounds found in G. catenatum makes it necessary to further investigate the fate of these compounds in the food web and to develop appropriate screening and detection methods.

\section{Acknowledgments}

We would like to express our sincere gratitude to Kathi Lefebvre and Vera Trainer from the NOAA Northwest Fisheries Science Center. PRC was supported through the FCT Investigator Program (IF/00271/2013).

\section{Author Contributions}

All authors contributed significantly to this study. P.R.C. conceived of the project and A.R. and P.R.C. designed the experiments. P.R.C was involved in the sample collection and culture of G. catenatum. A.R. provided in depth training to P.R.C. in mass spectrometry analysis and interpretation of mass spectra. A.R. and M.A.Q developed the analytical methods. A.R. and P.R.C. 
performed the experiments. M.A.Q. prepared the GC toxin reference materials for this project. All authors were involved in data analysis, data interpretation, and preparation of the manuscript.

\section{Conflicts of Interest}

The authors declare no conflict of interest.

\section{References}

1. Estrada, M.; Sanchez, F.J.; Fraga, S. Gymnodinium catenatum Graham en las rias gallegas (NO España). Investig. Pesq. 1984, 48, 31-40.

2. Franca, S.; Almeida, J.F. Paralytic shellfish poisons in bivalve molluscs on the Portuguese coast caused by a bloom of the dinoflagellate Gymnodinium catenatum. In Red Tides: Biology, Environmental Science and Toxicology; Okaichi, T., Anderson, D.M., Nemoto, T., Eds.; Elsevier: New York, NY, USA, 1989; pp. 93-96.

3. Mee, L.D.; Espinosa, M.; Diaz, G. Paralytic shellfish poisoning with a Gymnodinium catenatum red-tide on the Pacific coast of Mexico. Mar. Environ. Res. 1986, 19, 77-92.

4. Llewellyn, L.E.; Dodd, M.J.; Robertson, A.; Ericsona, G.; de Koning, C.; Negri, A.P. Post-mortem analysis of samples from a human victim of a fatal poisoning caused by the xanthid crab, Zosimus aeneus. Toxicon 2002, 40, 1463-1469.

5. García, C.; Bravo, M.C.; Lagos, M.; Lagos, N. Paralytic shellfish poisoning: post-mortem analysis of tissue and body fluid samples from human victims in the Patagonia fjords. Toxicon 2004, 43, 149-158.

6. Rodrigues, S.M.; Carvalho, M.; Mestre, T.; Ferreira, J.J.; Coelho, M.; Peralta, R.; Vale, P. Paralytic shellfish poisoning due to ingestion of Gymnodinium catenatum contaminated cockles-Application of the AOAC HPLC Official Method. Toxicon 2012, 59, 558-566.

7. Kao, C.Y.; Nishiyama, A. Actions of saxitoxin on peripheral neuromuscular systems. J. Physiol. 1965, 180, 50-66.

8. Ritchie, J.M.; Rogart, R.B. The binding of saxitoxin and tetrodotoxin to excitable tissue. Rev. Physiol. Biochem. Pharmacol. 1977, 79, 1-49.

9. Narahashi, T.; Moore, J.W. Neuroactive agents and nerve membrane conductances. J. Gen. Physiol. 1968, 51, 93-101.

10. Lagos, M.; Andrinolo, D. Paralytic shellfish poisoning (PSP): Toxicology and kinetics. In Seafood and Freshwater Toxins; Botana, L.M., Ed.; Marcel Dekker: New York, NY, USA, 2000; pp. 203-215.

11. Genenah, A.A.; Shimizu, Y. Specific toxicity of paralytic shellfish poisons. J. Agric. Food. Chem. 1981, 29, 1289-1291.

12. Oshima, Y. Postcolumn derivatization liquid-chromatography method for paralytic shellfish toxins. J. AOAC Int. 1995, 78, 528-532.

13. Catterall, W.A. Neurotoxins that act on voltage-sensitive sodium channels in excitable membranes. Annu. Rev. Pharmacol. Toxicol. 1980, 20, 15-43. 
14. Negri, A.P.; Stirling, D.; Quilliam, M.; Blackburn, S.; Bolch, C.; Burton, I.; Eaglesham, G.; Thomas, K.; Walter, J.; Willis, R. Three novel hydroxybenzoate saxitoxin analogues isolated from the dinoflagellate Gymnodinium catenatum. Chem. Res. Toxicol. 2003, 16, 1029-1033.

15. Llewellyn, L.; Negri, A.; Quilliam, M. High affinity for the rat brain sodium channel of newly discovered hydroxybenzoate saxitoxin analogues from the dinoflagellate Gymnodinium catenatum. Toxicon 2004, 43, 101-104.

16. Negri, A.P.; Bolch, C.J.S.; Geier, S.; Green, D.H.; Park, T.; Blackburn, S.I. Widespread presence of hydrophobic paralytic shellfish toxins in Gymnodinium catenatum. Harmful Algae 2007, 6, 774-780.

17. Vale, P. Complex profiles of hydrophobic shellfish poisoning compounds in Gymnodinium catenatum identified by liquid chromatography with fluorescence detection and mass spectrometry. J. Chromatogr. A 2008, 1195, 85-93.

18. Anderson, D.M. Red tides. Sci. Am. 1994, 271, 62-68.

19. Van Dolah, F.M. Marine algal toxins: Origins, health effects, and their increased occurrence. Environ. Health Perspect. 2000, 108, 133-141.

20. Moita, T.M.; Oliveira, P.B.; Mendes, J.C.; Palma, A.S. Distribution of chlorophyll a and Gymnodinium catenatum associated with coastal upwelling plumes off central Portugal. Acta Oecol. 2003, 24, S125-S132.

21. Vale, P.; Botelho, M.J.; Rodrigues, S.M.; Gomes, S.S.; Sampayo, M.A.M. Two decades of marine biotoxin monitoring in bivalves from Portugal (1986-2006): A review of exposure assessment. Harmful Algae 2008, 7, 11-25.

22. Moita, M.T.; Palma, S.; Oliveira, P.B.; Vidal, T.; Silva, A.; Vilarinho, M.G. The return of Gymnodinium catenatum after 10 years: Bloom initiation and transport off the Portuguese coast. In Proceedings of the 12th International Conference on Harmful Algae, Copenhagen, Denmark, 4-8 September 2006; Intergovernmental Oceanographic Commission (IOC) of UNESCO: Copenhagen, Denmark, 2008; p. 242.

23. Hall, S.; Strichartz, G.; Moczydlowski, E.; Ravindran, A.; Reichardt, P.B. The saxitoxins. In Marine Toxins: Origin, Structure and Molecular Pharmacology; Hall, S., Strichartz, G., Eds.; ACS Symposium Series, Washington, DC, USA, 1990; Volume 418, pp. 29-65.

24. Krock, B.; Seguel, C.G.; Cembella, A.D. Toxin profile of Alexandrium catenella from Chilean coast as determined by liquid chromatography with fluorescence detection and liquid chromatography coupled with tandem mass spectrometry. Harmful Algae 2007, 6, 734-744.

25. Graham, H.W. Gymnodinium catenatum, a new dinoflagellate from the Gulf of California. Trans. Am. Microsc. Soc. 1943, 62, 259-261.

26. Hallegraef, G.M.; Blackburn, S.I.; Doblin, M.A.; Bolch, C.J.S. Global toxicology, ecophysiology and population relationships of the chainforming PST dinoflagellate Gymnodinium catenatum. Harmful Algae 2012, 14, 130-143.

27. Amorim, A.; Dale, B. Historical cyst record as evidence for the recent introduction of the dinoflagellate Gymnodinium catenatum in the north-eastern Atlantic. Afr. J. Mar. Sci. 2006, 28, 193-197. 
28. Ribeiro, S.; Amorim, A.; Andersen, T.J.; Abrantes, F.; Ellegaard, M. Reconstructing the history of an invasion: the toxic phytoplankton species Gymnodinium catenatum in the Northeast Atlantic. Biol. Invas. 2012, 14, 969-985.

29. Moita, M.T.; Vilarinho, M.G.; Palma, A.S. On the variability of Gymnodinium catenatum Graham blooms in Portuguese waters. In Harmful Algae; Reguera, B., Blanco, J., Fernández, M.L., Wyatt, T., Eds.; Xunta de Galicia and Intergovernmental Oceanographic Commission of UNESCO, Santiago de Compostela: Amsterdam, The Netherlands, 1998; pp. 118-121.

30. Franca, S.; Alvito, P.; Sousa, I.; Gago, A.; Rodríguez-Vásquez, J.A.; Leão, J.M.; Comesaña, M.; Thibault, P.; Burdaspal, P.; Bustos, J.; et al. The toxin profile of some PSP toxin producing dinoflagellates occurring in Portuguese coastal waters as determined by alternative analytical methods. In Harmful and Toxic Algal Blooms; Yasumoto, T., Oshima, Y., Fukuyo, Y., Eds.; Intergovernmental Oceanographic Commission of UNESCO: Paris, France, 1996; pp. 519-522.

31. Flynn, K.J.; Flynn, K; John, E.H.; Reguera, B.; Reyero, M.I.; Franco, J.M. Changes in toxins, intracellular and dissolved free amino acids of the toxic dinoflagellate Gymnodinium catenatum in response to changes in inorganic nutrients and salinity. J. Plank. Res. 1996, 18, 2093-2111.

32. Band-Schmidt, C.; Bustillos-Guzman, J.; Morquecho, L.; Gárate-Lizárraga, I.; Alonso-Rodríguez, R.; Reyes-Salinas, A.; Erler, K.; Luckas, B. Variations of PSP toxin profiles during different growth phases in Gymnodinium catenatum (Dinophyceae) strains isolated from three locations in the Gulf of California, Mexico. J. Phycol. 2006, 42, 757-768.

33. Oshima, Y.; Blackburn, S.I.; Hallegraeff, G.M. Comparative study on paralytic shellfish toxin profiles of the dinoflagellate Gymnodinium catenatum from three different countries. Mar. Biol. 1993, 116, 471-476.

34. Negri, A.P.; Bolch, C.J.S.; Blackburn, S.I.; Dickman, M.; Llewellyn, L.E.; Méndez, S. Paralytic shellfish toxins in Gymnodinium catenatum strains from six different countries. In Harmful Algal Blooms 2000; Hallegraef, G.M., Blackburn, S.I., Bolch, C.J., Lewis, R.J., Eds.; Intergovernmental Oceanographic Commission of UNESCO: Paris, France, 2001; pp. 210-213.

35. Anderson, D.M.; Jacobson, D.M.; Bravo, I.; Wrenn, J.H. The unique, microreticulate cyst of the naked dinoflagellate Gymnodinium catenatum. J. Phycol. 1998, 24, 255-262.

36. Amorim, A.; Dale, B.; Godinho, R.; Brotas, V. Gymnodinium catenatum-like cysts (Dinophyceae) in recent sediments from the coast of Portugal. Phycologia 2002, 40, 572-582.

37. Lawrence, J.F.; Niedzwiadek, B.; Menard, C. Quantitative determination of paralytic shellfish poisoning toxins in shellfish using prechromatographic oxidation and liquid chromatography with fluorescence detection: Collaborative study. J. AOAC Int. 2005, 88, 1714-1732.

38. European Commission (EC) Regulation No. 1664/2006 of the European Parliament and of the Council of 6 November 2006. Off. J. Eur. Commun. 2006, L320, 13-45.

39. Perez, S.; Vale, C.; Botana, A.M.; Alonso, W.; Vieytes, M.R.; Botana, L.M. Determination of toxicity equivalent factors for paralytic shellfish toxins by electrophysiological measurements in cultured neurons. Chem. Res. Toxicol. 2001, 24, 1153-1157.

40. Costa, P.R.; Moita, T.; Rodrigues, S.M. Estimating the contribution of $N$-sulfocarbamoyl paralytic shellfish toxin analogs GTX6 and C3+4 to the toxicity of mussels (Mytilus galloprovincialis) over a bloom of Gymnodinium catenatum. Harmful Algae 2014, 31, 35-40. 
41. Costa, P.R.; Pereira, P.; Guillherme, S.; Barata, M.; Santos, M.A.; Pacheco, M.; Pousão-Ferreira, P. Hydroxybenzoate paralytic shellfish toxins induce transient GST activity depletion and chromosomal damage in white seabream (Diplodus sargus). Mar. Environ. Res. 2012, 79, 63-69.

42. Vale, P. Fate of benzoate paralytic shellfish poisoning toxins from Gymnodinium catenatum in shellfish and fish detected by pre-column oxidation and liquid chromatography with fluorescence detection. J. Chromatogr. A 2008, 1190, 191-197.

43. Van Dolah, F.M.; Fire, S.E.; Leighfield, T.A.; Mikulski, C.M.; Doucette, G.J. Determination of paralytic shellfish toxins in shellfish by receptor binding assay: collaborative study. J. AOAC Int. 2012, 95, 795-812.

44. Van Dolah, F.M.; Leighfield, T.A.; Doucette, G.J.; Bean, L.; Niedzwiadek, B.; Rawn, D.F.K. Single-laboratory validation of the microplate receptor binding assay for paralytic shellfish toxins in shellfish. J. AOAC Int. 2009, 92, 1705-1713.

45. Costa, P.R.; Botelho, M.J.; Lefebvre, K.A. Characterization of paralytic shellfish toxins in seawater and sardines (Sardina pilchardus) during blooms of Gymnodinium catenatum. Hydrobiologia 2010, 655, 89-97.

46. Lefebvre, K.A.; Bill, B.D.; Erikson, A.; Baugh, K.A.; O’Rourke, L.; Costa, P.R.; Nance, S.; Trainer, V.L. Characterization of intracellular and extracellular saxitoxin levels in both field and cultured Alexandrium spp. samples from Sequim Bay, Washington. Mar. Drugs 2008, 6, 103-116.

47. Quilliam, M.A.; Hess, P.; Dell'Aversano, C. Recent developments in the analysis of phycotoxins by liquid chromatography-mass spectrometry. In Mycotoxins and Phycotoxins in Perspective at the Turn of the Century; DeKoe, W.J., Samson, R.A., van Egmond, H.P., Gilbert, J., Sabino, M., Eds.; Publisher: Wageningen, The Netherlands, 2011; pp. 383-391.

48. Dell'Aversano, C.; Hess, P.; Quilliam, M.A. Hydrophillic interaction liquid chromatography-mass spectrometry for the analysis of paralytic shellfish poisoning (PSP) toxins. J. Chromatogr. A 2005, 1081, 190-201.

(C) 2015 by the authors; licensee MDPI, Basel, Switzerland. This article is an open access article distributed under the terms and conditions of the Creative Commons Attribution license (http://creativecommons.org/licenses/by/4.0/). 